\title{
X-ray Excited Optical Luminescence (XEOL) and X- ray Absorption Fine Structures (XAFS) Studies of Gold(I) Complexes with Diphosphine and Bipyridine Ligands
}

Pil-Sook G. Kim,${ }^{* \dagger}{ }^{\dagger}$ Yongfeng Hu, ${ }^{\ddagger}$ Marie-C. Brandys, ${ }^{\dagger}$ Tara J. Burchell,${ }^{\dagger}$ Richard J. Puddephatt, ${ }^{\dagger}$ and Tsun K. Sham ${ }^{*}{ }^{\dagger}$

${ }^{\dagger}$ Department of Chemistry, University of Western Ontario, London, ON N6A 5B7 Canada

${ }^{\ddagger}$ Canadian Light Source, University of Saskatchewan, Saskatoon, SK S7N 0X4 Canada

Supproting Information:

Figure S1. $\mathrm{k}^{2}$-weighted fine structures of complex 1-5 and 8-9. 


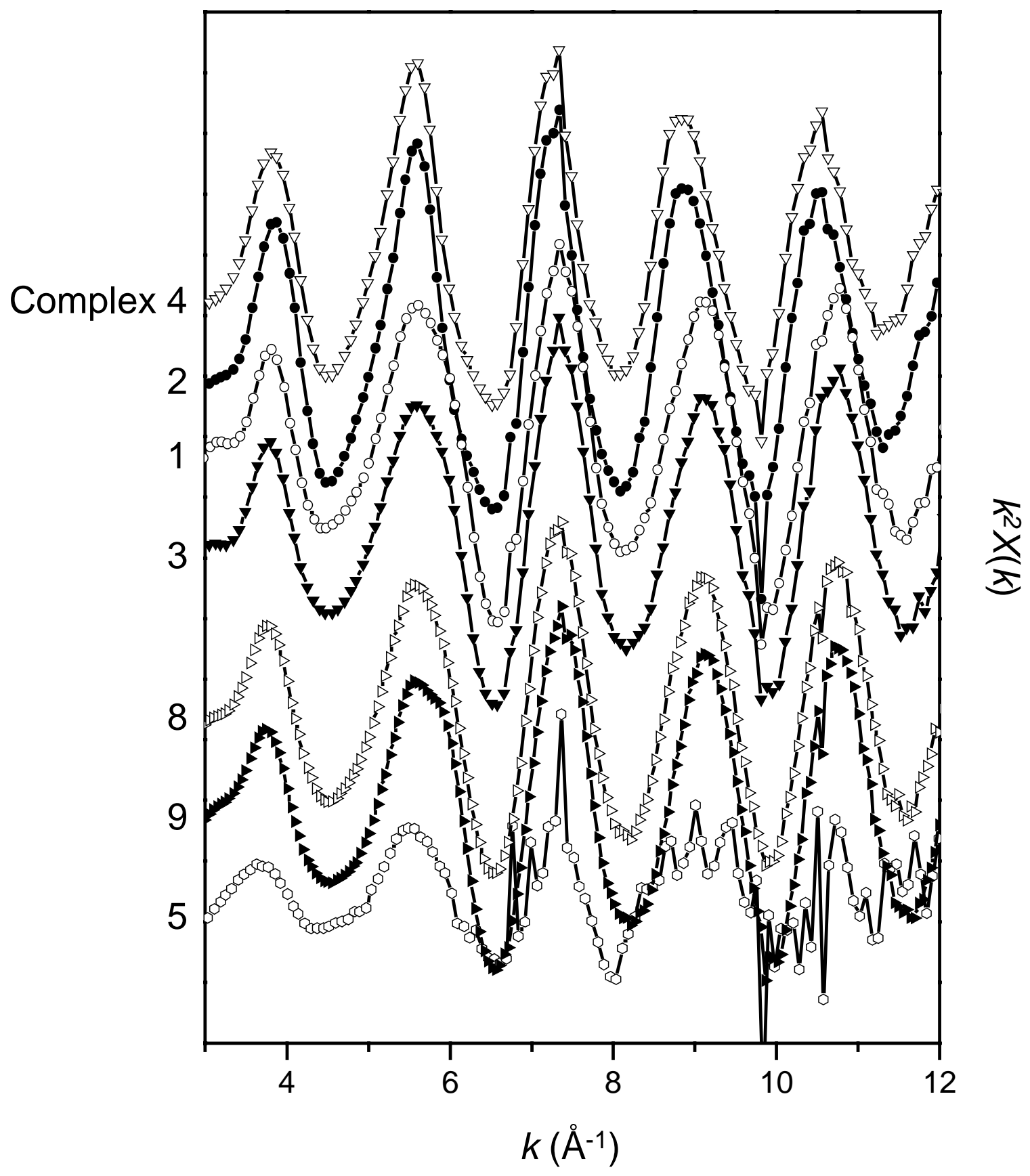

Figure S1. $\mathrm{k}^{2}$-weighted fine structures of complex 1-5 and 8-9. 